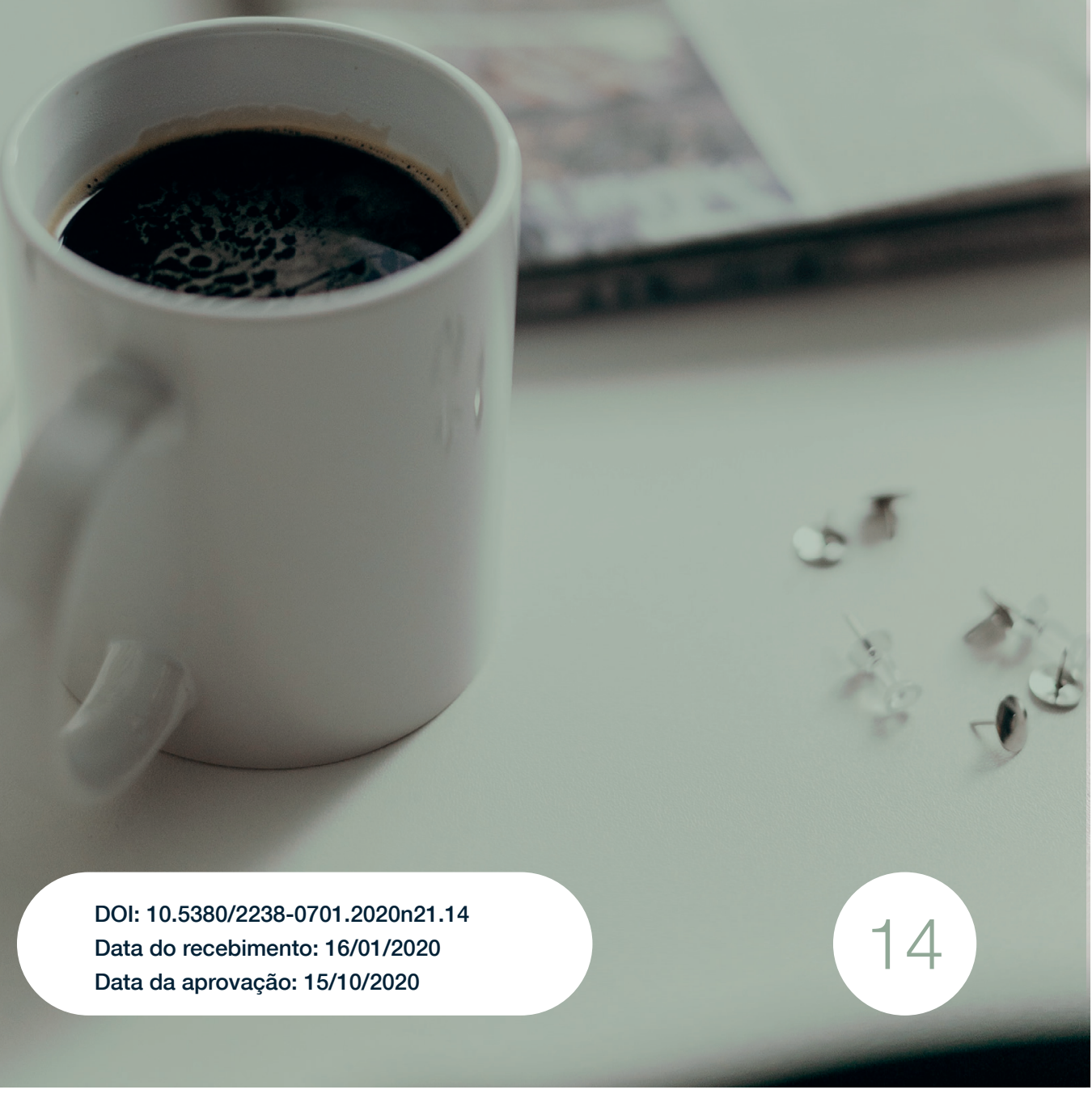


Uma Voz jornalística durante o regime militar no Paraná: Livro do jornalista Diego Antonelli recupera história da Voz do Paraná, que circulou entre 1956 e 1986, em Curitiba 


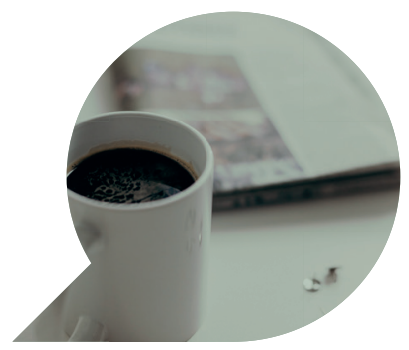

\section{Uma Voz jornalística durante o regime militar no Paraná}

\section{Livro do jornalista Diego Antonelli recupera história da Voz do Paraná, que circulou entre 1956 e 1986, em Curitiba}

SERGIO LUIZ GADINI ${ }^{1}$

Resumo: O texto apresenta, em forma de resenha, o livro "Jornal Voz do Paraná: uma história de resistência" (2019), da autoria de Diego Antonelli. Resultado de uma recente pesquisa histórica e jornalística, o autor recupera a trajetória de um periódico impresso que surge em 1956, a partir da Igreja Católica, e aos poucos amplia a projeção e alcance editorial, chegando a contribuir como espaço de expressão plural, pautando temas silenciados pelos demais meios de comunicação, durante o regime militar (1964-85). O livro preenche um dos vazios em torno da ausência de material bibliográfico e de pesquisa sobre os sombrios tempos da ditadura em um Estado (Paraná) fora do eixo do controle político nacional.

Palavras-chave: Voz do Paraná; Jornalismo paranaense; história da imprensa.

1 Doutor em Ciências da Comunicação, professor de Jornalismo da Universidade Estadual de Ponta Grossa (UEPG), coordenador do Ms em Jornalismo da UEPG. 
É possível que nos 19 cursos de Jornalismo ainda existentes no Paraná - numero que já chegou a 25 em instituições em todo Estado - pouco (ou quase nada) se fale da existência da Voz do Paraná. Muito provavelmente, por desconhecimento e ausência de registro da própria história do veículo. A partir de agora, se depender deste livro, não há mais motivo para silenciar: a Voz do Paraná tem - ao menos, deve ter - espaço assegurado nos cursos de Jornalismo espalhados por 10 cidades paranaenses.

O livro, nesta perspectiva, cumpre duas tarefas importantes na história da mídia paranaense: recupera a trajetória de um periódico impresso regional e, por tabela, ajuda a derrubar a lenda (mentira?) de que no Paraná a ditadura não teria sido tão 'sanguinária' como em outras regiões do País.

Vale um parêntesis para situar que no período que vai do pós-guerra aos anos 1970 instituições lutavam para criar e manter periódicos impressos, como parte de estratégias na disputa pela opinião pública e busca de legitimidade social. Na Igreja Católica, não era diferente. Além do tradicional semanário O São Paulo, editado pela arquidiocese de São Paulo, a Igreja criou diversos outros jornais em diversos estados e cidades do País.

Em Ribeirão Preto (SP), o mesmo fundador da Voz do Paraná - o bispo dom Manuel da Silveira D’Elboux - havia comprado o Diário de Notícias, que se torna um diário católico oficial, já no início dos anos 1940. Transferido para Curitiba, dom Manuel idealiza e lança a Voz, que passa a circular em 27/05/1956, como periódico voltado aos fiéis da Igreja na arquidiocese de Curitiba, ficando cerca de uma década e meia (até 1971) restrito às "sacristias e portas da igreja", como diz Antonelli (p. 11).

Após comprar uma gráfica de um grupo adventista paulista, a produção do semanário fica sob responsabilidade dos padres claretianos por 12 anos (até 1968), com a publicação de 616 edições, sob chefia do padre Wanderlan Lombardo Gama e direção do também claretiano Geraldo Meneses, nos fundos da I greja Imaculado Coração de Maria, na rua Nunes Machado, 975, região central de Curitiba.

Oportuno lembrar que é também nesta época (1950/60) que a Igreja Católica adquire diversas emissoras radiofônicas no Paraná: Curitiba, Lapa, Palmeira, Paranaguá, Antonina, Araucária e Ponta Grossa (Rádio Sant'Ana, em 1961). "A maior parte da produção desse período era de- 
dicada aos temas da Igreja Católica", diz o autor (p. 15). E, de certo modo, os debates e notícias também reproduziam a versão oficial anticomunista, em uma das versões (capitalistas) da Guerra Fria pós-1945. O Voz do Paraná também alinha editorialmente com a versão do golpe militar de 1964, contrário às reformas de base do governo João Goulart (1961-64), derrubado pelo golpe civil-militar, também articulado nos escritórios da CIA em diversos países da América Latina.

A primeira reformulação gráfica do semanário acontece em 1964, quando o jornal deixa de ser tabloide e passa a circular em formato standard, embora a linha editorial seguia a toada do golpismo de plantão, com uma tiragem semanal de 15 mil exemplares.

Com a saída dos claretianos da gestão, em 1968, o Voz do Paraná passa a ser administrado por um grupo de leigos católicos, mudando a sede para o bairro do Ahú (Rua Francisco Scremin, 1855), sob edição da Editora Voz do Paraná (Evopar), que também funcionava como gráfica, a partir de 1970. Entre os sócios, todos leigos e também ligados e 'bem relacionados' com o regime militar no Estado: Roaldo Amundsen Koehler, João Átila Rocha, José Maria Munhoz da Rocha, Giocondo Villanova Artigas, Euro Brandão, Marcos Baggio e Geraldo Dallagrave. Embora mantivesse a linha católica, a Voz do Paraná passa a ser gerida por um grupo comercial.

Diretor clínico do Hospital Nossa Senhora das Graças, o médico Roaldo Koehler tem o trânsito necessário para ampliar as relações (comerciais e políticas) e revela uma paixão pelo jornalismo, dedicando-se diuturnamente ao projeto e trabalhos profissionais. Responsável financeiro pela Voz do Paraná, colaboradores afirmam que, em várias situações, Roaldo usou dinheiro próprio para manter o periódico em circulação. Profissionais que conviveram com Roaldo confirmam que ele não partilhava das práticas repressivas do regime militar e tampouco censurou qualquer matéria no periódico.

E, assim, a partir de 1970, Aroldo Murá se torna o jornalista responsável e depois passa a ser sócio da Voz do Paraná com o desafio de "tirar a 'Voz' das sacristias e colocá-la como uma das protagonistas na história da imprensa estadual”, avalia Antonelli (p. 31). Começa, aí, a outra fase da Voz do Paraná!

Com um reforço na equipe profissional, a partir daí, aos poucos a Voz ganha espaço como mídia local e também estadual, exatamente no 
vazio e silêncio que os demais periódicos deixavam, frente aos incontáveis desmandos do regime militar, com desdobramentos em Curitiba e em todo Paraná. Celso Nascimento, Dinah Pinheiro, Luiz Manfredini, Francisco dos Santos, José Roberto Oliva, Lúcia Nórcio, Teresa Urban, Ruth Bolognese, Valêncio Xavier, Dante Mendonça, Toninho Vaz, Szyja Lorber, Luiz Fernando de Queiróz, Walter Schmidt, Juabal Dohms, dentre vários outros, foram profissionais que passaram pela redação da Voz do Paraná em um momento (anos 1970) que era difícil não só trabalhar com jornalismo, como também conseguir emprego sem ser diuturnamente importunado pela censura da ditadura militar.

"Um dos grandes desafios para os jornalistas que integraram a equipe da Voz do Paraná era fazer um jornal que tivesse características de uma revista, mas que não perdesse o espírito de um jornal", conta Celso Nascimento (p. 53). "Era preciso pensar em pautas elaboradas. Tinha que escrever o factual de quarta para durar até domingo", completa. E, além disso, destaca Maí Nascimento, "era preciso opinar numa época em que opinar era proibido".

E como se faz para legitimar e consolidar um título jornalístico? A partir de "grandes coberturas jornalísticas", afirma o autor (p. 57). E foi assim que a Voz do Paraná, a partir do início dos anos 1970 se torna um diferencial na cidade, na esteira da falta de cobertura jornalística independente na Cidade e no Estado. "Com um time experiente, a lista de reportagens de peso produzidas pela Voz é considerada extensa", avalia Antonelli.

Foi assim com a queda do governador Haroldo Leon Peres, em março de 1971, quando a Voz do Paraná é o "único jornal a registrar com detalhes a queda do governador", que era nomeado pelo regime militar. Oportuno lembrar que, na época, a "imprensa brasileira era tomada pela censura", contextualiza o autor. "O jornal não era comunista, eu não era. Nós fomos fazendo um jornal respeitável. Havia pressões de fora? Havia. Da área política e também da igreja. Mas nós segurávamos as pontas", conta o ex-diretor da Voz do Paraná, Aroldo Murá (p. 63).

Diego Antonelli destaca que, além da censura,

"a repressão praticada pelo governo militar tomou proporções sociais imensas. O grupo Tortura Nunca Mais estima que foram quatro mil presos durante a ditadura apenas no Paraná. Desses, no mínimo, mil sofreram tortura no estado. O número pode ser muito superior. Quatro cidades tornaram-se sedes dos principais centros 
de tortura no estado: Curitiba, Apucarana, Foz do Iguaçu e Ponta Grossa" (Antonelli, 2019, p. 64).

A Voz do Paraná também assumiu um papel de espaço solidário a profissionais vítimas do regime militar. Este é o caso do José Benedito Pires Trindade, Milton Ivan Heller, Luiz Manfredini e Teresa Urban, todos que enfrentaram o regime ditatorial e também passaram pela redação da Voz do Paraná, até porque boa parte dos veículos, alinhados ao regime, não abria espaço para jornalistas listados pela repressão.

E, assim, na mesma linha editorial do semanário O São Paulo, da arquidiocese paulista, que questionava os desmandos, abusos e desrespeitos do regime militar, principalmente aos direitos humanos, a Voz do Paraná, guardadas as proporções, assume um papel similar em nível regional, a partir do Estado, onde também havia desmandos que precisavam ganhar as páginas dos impressos, que estavam sob controle do olho de censores. "(A Voz) levava à sociedade, então sufocada pela ditadura, uma informação clara, objetiva, respeitável, que muitas vezes não era encontrada em outros veículos", avalia Luiz Manfredini.

Um dos espaços editoriais lançados pelo jornal registrou importante repercussão, como relata a jornalista Maria Luiza Mendonça (Maí), que entrou na Voz em 1975:

\footnotetext{
"Meu trabalho mais frequente na 'Voz' foi o Roda Vida, uma grande entrevista de pergunta-resposta, gravada em fita cassete, que ocupava as duas páginas centrais do semanário. Participava da entrevista e degravava/editava o conteúdo. Foram dezenas, durante meus cinco anos de Voz do Paraná. Algumas, realmente memoráveis" (Antonelli, 2019, p. 124).
}

Dentre diversas coberturas, e denúncias exclusivas, a Voz do Paraná ficou caracterizada como o único periódico paranaense que contou com um correspondente (Celso Nascimento) na III Conferência Geral do Episcopado Latino-Americano, realizada no México, entre 27/01 e 13/02 de 1979, conhecida como Conferência de Puebla, que rediscute o papel da Igreja diante do aumento da pobreza e da desigualdade social nos países latinos, muitos dos quais sob governos ditatoriais e golpistas, que pouco respeitavam democracia e direitos humanos.

Em 1981, quando a Voz do Paraná já estava sediada no Centro Cívico de Curitiba (Rua Alberto Folloni, 125), Celso Nascimento deixa o jornal e a edição fica sob responsabilidade de Francisco de Abreu Duarte. 
E em 1982, Aroldo Murá também se afasta do jornal, quando o periódico ainda contava com cerca de 10 mil assinantes. Com outras mudanças e troca de funções, o jornal circula ainda até outubro de 1985 e no ano seguinte o título (Voz do Paraná) é repassado à gestão da PUC-PR, sob direção do ex-ministro e ex-reitor Euro Brandão, mas o periódico muda de nome (e passa a ser Atualidade). Em 1996, o jornal retoma o título histórico de Voz do Paraná e, poucos anos depois, é renomeado para Voz da Igreja, sob gestão da Arquidiocese de Curitiba. Era o fim de uma era que registra três décadas sob um projeto editorial que surge na igreja (em 1956) e amplia circulação até 1986.

E quem é o autor do livro? Jornalista (de formação e conhecimento profissional, graduado pela UEPG), mestre em Comunicação pela UFPR, Diego Antonelli sustenta a abordagem do livro em uma pesquisa histórica nos arquivos e acervo do jornal, além de entrevistas inéditas com profissionais responsáveis pela produção semanal da Voz do Paraná (1956-1986), em diversos momentos da história do periódico.

"Os principais protagonistas da Voz do Paraná desempenharam papel significativo na história da própria imprensa paranaense, tão carente de obras de pesquisa capazes de reconstituir o passado, ainda que não tão distante", afirma o também jornalista, advogado e professor Hélio Puglielli, no prefácio do livro.

Pela pesquisa, diz o autor, a Voz do Paraná foi

\begin{abstract}
"um jornal que deixou as sacristias para colocar seu nome em um lugar especial na história da imprensa paranaense. Uma época em que — certamente — o jornal conseguiu fazer da função primária do jornalismo, a informação, uma ferramenta que, dentro de suas possibilidades, certamente contribuiu para avanços na sociedade e a consolidação da democracia no país" (Antonelli, 2019, p. 96).
\end{abstract}

A partir de temas pouco presentes nos demais periódicos que circulavam no Paraná, a Voz consegue, de fato, expressar o desrespeito aos direitos humanos e também agir como espaço de debate sobre problemas sociais que marcaram os anos 1970 até o fim do regime militar.

Um periódico precisa de estratégias e, fundamentalmente, de atores e dirigentes que assumam a publicação. Além de jornalistas, o médico Roaldo Amundsen Koehler, que ficou na direção do periódico por longos anos, é uma das personagens responsáveis pelo projeto editorial. Koehler dirigiu a Voz de 1968 até início dos anos 1980, quando se afasta gradativamente por problemas de saúde, e morre em 30/10/1984, aos 
68 anos. Antonelli relata o envolvimento do principal administrador da Voz do Paraná, a partir do depoimento de Aroldo Murá G. Haygert, que coordenou a produção jornalística de 1970 até 1982:

"...o Publisher não perseguia os holofotes, não visitava autoridades, não paparicava ninguém. A não ser dom Pedro Fedalto, o arcebispo, a quem visitava semanalmente, muitas vezes acompanhado de outro médico, o companheiro mariano Ary de Christan, major médico do Exército, quem, desconfio, deixava-o a par de movimentos (declináveis) das casernas. Ary era médico do general Orlando Geisel, irmão do general Ernesto, que foi presidente no período do Regime Militar" (Antonelli, 2019, p. 119).

Trata-se, enfim, de uma pesquisa necessária — agora em formato de livro - para registrar a história de um semanário que surge como periódico religioso e passa a exercer importante papel em um dos momentos em que a agressão aos direitos humanos avançava nos porões do regime militar (1964-1985) em todo o País. 


\section{REFERÊNCIAS}

ANTONELLI, Diego. Jornal Voz do Paraná: uma história de resistência. Curitiba: Editora Esplendor, 2019.

Data do recebimento: 16 janeiro 2020

Data da aprovação: 15 outubro 2020 


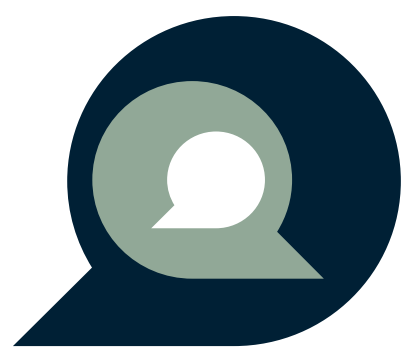

